\title{
Conformational Changes of Vitamin D Receptor as a Potential Cause of Multiple Sclerosis
}

\author{
Miskic $\mathrm{B}^{1 *}$, $\operatorname{Cosc} \mathrm{V}^{1}$, Miskic $\mathrm{K}^{2}$ and Rajkovaca $\mathrm{I}^{3}$ \\ ${ }^{1}$ Faculty of Dental Medicine and Health Osijek, Croatia \\ ${ }^{2}$ Faculty of Dental Medicine Rijeka, Croatia \\ ${ }^{3}$ Department of gastroenetrologie, endocrinologie and diabetologie, Croatia
}

Received: 眥 January 08, 2019; Published: 眥 January 25, 2019

*Corresponding author: Miskic B, Faculty of Dental Medicine and Health Osijek, Croatia

\begin{abstract}
Abbreviations: MS: Multiple Sclerosis; CNS: Nervous System; IL2RA: Interleukin-2Receptor Alpha Gene; IL7RA: Interleukin-7 Receptor Alpha Gene; EBV : Epstein-Barr Virus ; UTR: Untranslated Region; VDREs : Vitamin D Responsive Elements; VDR: vitamin D Receptor; miRNAs: MicroRNAs; SLE: Systemic lupus Erythematosus; RXR: Retinoid X Receptor; mRNAs: Messenger RNAs; EBV: Epstein-Barr virus
\end{abstract}

\section{Mini Review}

Multiple sclerosis (MS) is an autoimmune inflammatory disorder of unknown etiology affecting central nervous system (CNS)characterized by demyelination and variable degrees of axonal loss [1]. The etiology of MS is still unknown; however, it is believed to be caused by combination of immune dysregulation, genetic and environmental factors [2]. Recent studies have revealed severeal genes as risk factors including MHC HLA DR15/DQ6 allele being the strongest one, alleles of interleukin-2 receptor alpha gene (IL2RA) and interleukin-7 receptor alpha gene (IL7RA) have also been identified [3]. The pathogenesis of MS includes immune attack against CNS antigens through activation of CD4+ myelin-reactive $\mathrm{T}$ cells and a possible contribution by B cells [4]. Furthermore, there are some environmental factors related to increased risk of developing MS like Epstein-Barr virus (EBV) infection and vitamin D deficiency $[5,6,7]$. Prevalence of MS is increased in geographic areas further away from the equator [8]. This could be related to reduced sun exposure leading to vitamin $\mathrm{D}$ deficiency as a possible contributing factor $[6,7]$.

Also, studies have shown that higher levels of vitamin D could be protective in certain patient populations [9,10]. Recently, there is a growing number of studies showing how vitmin D deficiency is related to MS development. Approximately one billion people worldwide have vitamin D deficiency or insufficiency [11]. Vitamin D is a fat-soluble vitamin existing in two forms ergocalciferol (vitamin D2) and cholecalciferol (vitamin D3) which is more bioactive than vitamin D2. It can be consumed in food or synthesised in skin by sun exposure [12]. The vitamin D binding protein transports vitamin D3 to the liver where it is hydroxylated, this process results in the formation of 25-hydroxyvitamin D3 (25(OH)D3), the 25(OH)D3 metabolite is also hydroxylated by renal CYP27B1 to 1,25-dihydroxyvitamin D [1,25(OH)2D; calcitriol], the most bioactive vitamin D metabolite [13-15]. When calcitriol binds to the vitamin D receptor (VDR),it forms a nuclear heterodimer with the retinoid $\mathrm{X}$ receptor so this complex binds to genomic vitamin $\mathrm{D}$ response elements and downregulates expression of a variety of genes [16].

There are many binding patterns throughoutheterodimerisation or overlaps of vitamin D responsive elements (VDREs) in the DNA [17]. Furthermore, it is considered that conformational changes between retinoid X receptor (RXR) and vitamin D receptor (VDR) through their heterodimerisation can activate different signaling pathways resulting in production of a large number of proteins involved in cell function [18]. It is known that MS is more prevalent in higher latitudes, where sunlight is of lower intensity and several studies found that increased body exposure to sunlight is also associated with a decreased risk of MS, especially if the sun exposure occurred during childhood and adolescence [19-21]. Recently, it is found that the birth month is correlated with MS risk; individuals born in the fall (whose mothers were exposed to summer sunlight) have a low MS risk, whereas individuals born in the spring have a higher risk of MS [22]. This could be a possible association between sunlight exposure during pregnancy, vitamin D status and the risk of MS, but it is still unknown if provocative factor for MS is vitamin D deficiency or reduced sunlight exposure by itself. 
Also, there is a growing number of studies investigating intracellular pathways including vitamin D and VDR. As mentioned previously, these pathways are dependent on conformational changes between VDR and retinoid X receptor and they result in different signaling pathways activation and production of a large number of proteins involved in cell function, moreover VDR can autoregulate its own acitivity depending on vitamin D serum levels [23]. New studies are showing potential role of microRNA in VDR regulating pathways. MicroRNAs (miRNAs) are small non-coding RNA molecules that regulate the expression of multiple target genes by targeting the 3'-untranslated region (UTR) of messenger RNAs (mRNAs), resulting in degradation or translational repression of mRNA. In the immune system, miRNA modulate both innate and adaptive immune responses [24]. Altered miRNA expression has been reported in the pathology of autoimmune diseases, cancer and coronary artery disease and also it could be related to vitamin D deficiency [25-27].

There is a study of Chen et al. Showing how vitamin D deficiency reduced expression of miRNA in systemic lupus erythematosus (SLE), furthermore vitamin D supplement alter those miRNAs expression in isolated T cells from patients with SLE (25). This could be a potential cuase for other autoimmune diseases development, but for MS also. It is still unknown what are the "cut-off" levles of vitamin D for unfavorable immunological response so this should be investigated further. Considering this, it is known how serum levels of vitamin D are important for VDR pathways activation, but intracellular levels of vitamin D could also be essential. We think it is important to measure serum vitamin D levels, but also intracellular levels of vitamin D because it can give us more information about vitamin D concentration needed for normal cell function, it can help us detect vitamin D deficiency even though when its serum levels are normal. Future studies are needed to assess vitamin D deficiency mechanisms on intracellular levels and their influence on risk of developing MS.

\section{References}

1. Garg N, Smith TW (2015) An update on immunopathogenesis, diagnosis, and treatment of multiple sclerosis. Brain Behav 5(9): e00362.

2. Ascherio A, Munger KL (2007) Environmental risk factors for multiple sclerosis. Part I: the role of infection. Ann Neurol 61(4): 288-299.

3. Sawcer S, Hellenthal G, Pirinen M, Spencer CC, Patsopoulos NA, et al. (2011) Genetic risk and a primary role for cell-mediated immune mechanisms in multiple sclerosis. Nature 476(7359): 214-219.

4. Gold R, Linington C, Lassmann H (2006) Understanding pathogenesis and therapy of multiple sclerosis via animal models: 70 years of merits and culprits in experimental autoimmune encephalomyelitis research. Brain 129(8): 1953-1971.

5. Ascherio A, Munger KL (2007) Environmental risk factors for multiple sclerosis. Part I: the role of infection. Ann Neurol 61(4): 288-299.

6. Ascherio A, Munger KL (2007) Environmental risk factors for multiple sclerosis. Part II: noninfectious factors. Ann Neurol 61(6): 504-513.
7. Ascherio A, Munger KL, Simon KC (2010) Vitamin D and multiple sclerosis. Lancet Neurol 9(6): 599-612.

8. Simpson S Jr, Blizzard L, Otahal P, Van der Mei I, Taylor B (2011) Latitude is significantly associated with the prevalence of multiple sclerosis: a meta-analysis. J Neurol Neurosurg Psychiatry 82(10): 1132-1141.

9. Munger KL, Zhang SM, O’Reilly E, Hernán MA, Olek MJ, et al. (2004) Vitamin D intake and incidence of multiple sclerosis. Neurology 62(1): 60-65.

10. Munger KL, Levin LI, Hollis BW, Howard NS, Ascherio A (2006) Serum 25-hydroxyvitamin D levels and risk of multiple sclerosis. JAMA 296(23): 2832-2838.

11. Holick MF (2007) Vitamin D deficiency. N Engl J Med 357: 266-281.

12. Vieth R (1999) Vitamin D supplementation, 25-hydroxyvitamin D concentrations, and safety. Am J Clin Nutr 69(5): 842-856.

13. Bikle DD (2014) Vitamin D metabolism, mechanism of action, and clinical applications. Chem Biol 21(3): 319-329.

14. Christakos S, Ajibade DV, Dhawan P, Fechner AJ, Mady LJ (2010) Vitamin D: metabolism. Endocrinol Metab Clin North Am 39(2): 243-253.

15. Hollis BW (1996) Assessment of vitamin D nutritional and hormonal status: what to measure and how to do it. Calcif Tissue Int 58(1): 4-5.

16. Hanwell HE, Banwell B (2011) Assessment of evidence for a protective role of vitamin D in multiple sclerosis. Biochim Biophys Acta 1812(2): 202-212.

17. Rochel N, Wurtz JM, Mitschler A, Klaholz B, Moras D (2000) The crystal structure of the nuclear receptor for vitamin $\mathrm{D}$ bound to its natural ligand. Mol Cell 5(1): 173-179.

18. Evans RM, Mangelsdorf DJ (2014) Nuclear receptors, RXR, and the big bang. Cell 157(1): 255-266.

19. Bjørnevik K, Riise T, Casetta I, Drulovic J, Granieri E, et al. (2014) Sun exposure and multiple sclerosis risk in Norway and Italy: The EnvIMS study. Mult Scler 20(8):1042-1049.

20. Islam T, Gauderman WJ, Cozen W, Mack TM (2007) Childhood sun exposure influences risk of multiple sclerosis in monozygotic twins. Neurology 69(4): 381-388.

21. Lucas RM, Ponsonby AL, Dear K, Valery PC, Pender MP, et al. (2011) Sun exposure and vitamin D are independent risk factors for CNS demyelination. Neurology 76(6): 540-548.

22. Dobson R, Giovannoni G, Ramagopalan S (2013) The month of birth effect in multiple sclerosis: systematic review, meta-analysis and effect of latitude. J Neurol Neurosurg Psychiatry 84(4): 427-432.

23. Evans RM, Mangelsdorf DJ (2014) Nuclear receptors, RXR, and the big bang. Cell 157(1): 255-266.

24. Pauley KM, Cha S, Chan EK (2009) MicroRNA in autoimmunity and autoimmune diseases. J Autoimmun 32(3-4): 189-194.

25. Chen DJ, Li LJ, Yang XK, Tao Yu, Rui Xue Leng, et al. (2017) Altered microRNAs expression in T cells of patients with SLE involved in the lack of vitamin D. Oncotarget 8(37): 62099-62110.

26. Ma Y, Trump DL, Johnson CS (2014) Vitamin D and miRNAs in Cancer. Curr Gene Ther 14(4): 269-275.

27. Sheane BJ, Smyth P, Scott K, Aziz R, Buckley M, etal. (2015) An association between microRNA-21 expression and vitamin D deficiency in coronary artery disease. Microrna 4(1): 57-63. 
ISSN: 2574-1241

DOI: 10.26717/BJSTR.2019.13.002426

Miskic B. Biomed J Sci \& Tech Res

(c) (i) This work is licensed under Creative

Submission Link: https://biomedres.us/submit-manuscript.php

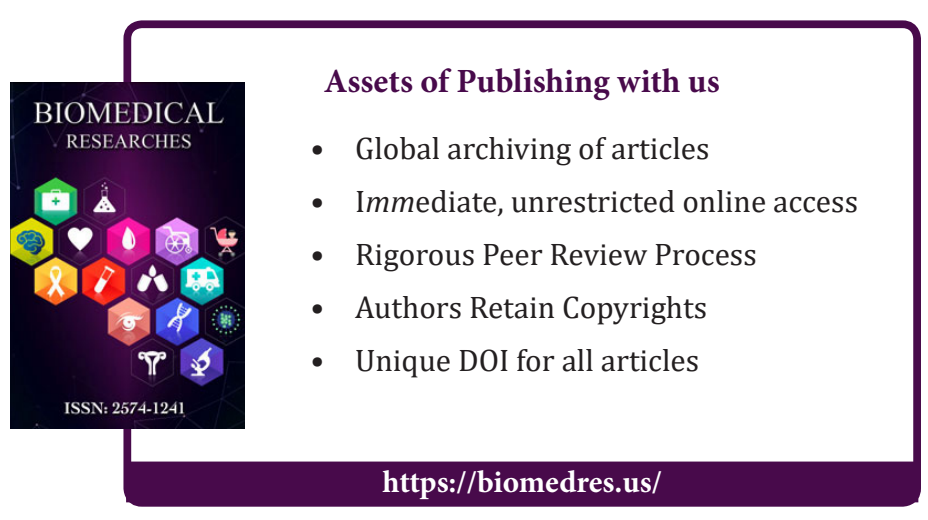

